\title{
Aggregation Behaviour and Interspecific Responses \\ in Three Species of Triatominae
}

\section{Alicia N Lorenzo Figueiras ${ }^{+}$, Claudio R Lazzari}

Departamento de Ciencias Biológicas, Facultad de Ciencias Exactas y Naturales, Universidad de Buenos Aires, Ciudad Universitaria (1428), Buenos Aires, Argentina

The response to intra- and interspecific assembling signals was tested in three species of Chagas' disease vectors. As previously described for Triatoma infestans, larvae of both species, T. sordida and $\mathrm{T}$. guasayana, aggregated on papers impregnated with their own excrement. Moreover, bugs belonging to each of the three species also aggregated on papers contaminated with faeces from the other two, with the only exception of the larvae of T. guasayana, which did not assemble on faeces of T. sordida. In all

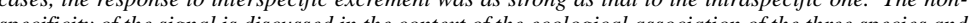

Key words: Triatominae - aggregation behaviour - interspecific communication - faeces

Triatoma infestans, T. sordida and T. guasayana are haematophagous bugs distributed over Bolivia, Brazil and Argentina. All three species are extremely important from a sanitary point of view because they transmit the flagellate Trypanosoma cruzi and are thus vectors of Chagas disease in South Amenica. Among them, T. infestans is the best adapted to domestic envilonm infesians is the

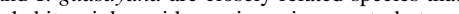

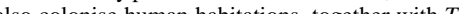
infestous (Lent \& Wygodzinst 1979). T. sodide in $T$. similarity and ove he two species can be discriminted by differen, varia species can be discrivibed by different ond rostral segment and the anteocular length (Lent \& Wygodzinsky 1979, Gorla et al. 1993).

It has been argued that if $T$ infestans could be eliminated from human housing, $T$ sordida and $T$. guasayana would colonise its empty niche. Indeed, such a replacement of $T$. infestans by $T$. sordida has been reported in Brazil (Schofield 1994). Therefore the knowledge of the factors af-

This investigation received financial support from the NDP/World Bank/WHO Specil Program fo and Trining Bin Tropica Special Program for Research the Universidad de Buenos Aires/Argentin ${ }^{+}$Corresponding author. Fax: +54-1-7820582. E-mail: aliciaf@bg.fcen.uba.ar

Received 14 March 1997

1997 fecting the ecological interaction between species becomes relevant. In addition, given their role as Chagas vectors, this knowledge could aid in the esign of control strategies.

Aggregation behaviour, as a response to chemical signals, has been reported in several species of Triatominae. Rhodnius prolixus, T. infestans, $T$. . 1971, Schald \& Mnch 1968, Baldwin et al. Pate 1977, Ondzat al 1986, Cru-Ló

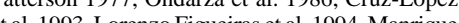
\& Lazzi 1995). The specificity of the signue (1993), who reported that an "interspecific agregation pherome" is present in the faeces of larvae and adults f several species of the subfamily Triatomina ( $T$ barberi, $T$, mazzottii, $T$. longipennis, $T$. pallidipennis and $R$. prolixus).

The present study was undertaken to examine he response of $T$. sordida, $T$. guasayana and $T$. infestans to aggregation substances present in their faeces. Experiments were conducted by testing the response of the bugs to both, intra- and interspecific putative aggregation signals present in bugs excrement.

\section{MATERIAIS AND METHODS}

Larvae of T. sordida and T. guasayana, reared on chicken, were obtained from the laboratory stock of the "Centro de Reservorios y Vectores, Servicio Nacional de Chagas, Cordoba, Argentina". Larvae of $T$. infestans, reared at $28^{\circ} \mathrm{C}$ and fed on heparinized bovine blood by means of an artificial feeder (Núnez \& Lazzari 1990), were obtained from our laboratory colony. 
For the obtention of the excrement, insects were placed in plastic containers bearing a plastic mes Faeces were collected on pieces of filter paper, placed below the insect containers, for 3 to 5 h after feeding. Any contact between the animal and the filter papers was carefully avoided to exclude other potential cues (Lorenzo Figueirs \& Lazzari 1996). The collected faeces were used 24 $\mathrm{hr}$ later (dry faeces). This time interval guarantees their aggregating activity (Lorenzo Figueiras et al. 1994).

The larval excrement of different species was examined for their ability to induce aggregation of the insects. The procedure has been previously described by Lorenzo Figueiras et al. (1994) Briefly, a circular glass arena ( $12 \mathrm{~cm}$ diameter) was divided in three sectors, and three pieces of filter paper $(3 \times 2 \mathrm{~cm})$ folded once, were placed one in each sector, $2 \mathrm{~cm}$ away from the wall. One pape was contaminated with dry faeces, while the other two remained clean, as controls. A group of larvae was carefully released in the centre of the aren. After $1 \mathrm{hr}$ the position of the bugs was recorded by counting the number of insects on each sector (i.e. $1 / 3$ of the total area of the arena). Nine to 12 insects were used for each trial. Room temperature $24-25^{\circ} \mathrm{C}$

The response to intra- and interspecific excrement was tested. The aggregation behaviour of $T$. sordida and $T$. guasayana to their own faeces an on $T$. infestans excrement was recorded. Crossaggregation of $T$. infestans on faeces of $T$. sordid
or $T$. guasayana was also tested. In addition, we or T. guasayana was also tested. In addition, we faces of $T$ guasayana and vice-vers Test infaeces of $T$. gusay and aice-versa. Test insects we thin an instar larva of $T$ infestens. Experinenta $T$. instar larvae of T. infestans. Expe

For each experimental series the distribution f the insects in the arena was statistically analyzed of the insects means of a G-test for goodness of fit to a rendom distribution (i.e., 1/3 for experimental zone

and $2 / 3$ for control zones). After testing for homogeneity (G-test for heterogeneity), data corresponding to the different replication of each asay were pooled. The aggregation responses were compared by means of two-factors ANOVA (factor 1 : species origin of faeces; factor 2: species of tes insects) and Tukey's test performed a posterior insects) and Tukey's test
for multiple comparisons.

The data about aggregation of $T$. infestans on their own faeces used in this paper for comparison, have been previously published (Lorenzo Figueiras et al. 1994)

\section{RESULTS}

Figure depicts the aggregation responses of the three species evoked by their own excrement, as well as by that belonging to the others. As previously shown for T. infestans (Lorenzo Figueiras et al. 1994), both, T. sordida and T. guasayana aggregated around papers impregnated with their own dry excrement. Larvae from both species chose those papers contaminated with their own faeces rather than clean ones. It could be established that T. sordida larvae significantly responded to $T$. guasayana excrement. However, the inverse response did not occur, i.e., faeces belonging to $T$. sordida were not able to assenble larvae of $T$. guasayana. When tested for their aggregation repecies, exhite gate are the experime assembling response was observed in $T$ infestans larvae tested with faeces of $T$. sordida or $T$. guasayana. The insects guasayana. The insects significan

The two-factor ANOVA showed that the responses of the three species differ that the responses of the three species differ significantly
$(\mathrm{F}=4.021 ; \mathrm{df}=2,60 ; \mathrm{P}=0.023)$. In general, larvae of $T$. guasayana exhibited a weaker aggregation response than T. sordida and T. infestans ( $\mathrm{Fig}$ ). No difference between the last two named species was observed. Concerning the origin of faeces, they revealed a significant difference of attractiveness on the insects $(\mathrm{F}=6.604 ; \mathrm{df}=2,60 ; \mathrm{P}=0.003)$

TABLE

Aggregation response of Triatoma guasayana T. sordida and T. infestans to larvae faeces of these species. G these species. $\mathrm{G}$ of insects for each serie

\begin{tabular}{lccccccccrr}
\hline Faeces of & \multicolumn{3}{c}{ T. sordida } & \multicolumn{3}{c}{ T. guasayana } & \multicolumn{3}{c}{ T. infestans } \\
\hline Test insects & $\mathrm{N}$ & $\mathrm{G}$ & $\mathrm{P}$ & $\mathrm{N}$ & $\mathrm{G}$ & $\mathrm{P}$ & $\mathrm{N}$ & $\mathrm{G}$ & $\mathrm{P}$ \\
\hline T. sordida & 63 & 7.8 & $<0.01$ & 41 & 42.9 & $<0.001$ & 64 & 6.2 & $<0.025$ \\
T. guasayana & 57 & 0.09 & $\mathrm{~N}$. S. & 45 & 62.0 & $<0.025$ & 84 & 11.4 & $<0.025$ \\
T. infestans & 89 & 4.2 & $<0.05$ & 59 & 32.0 & $<0.001$ & & $a$ & \\
\hline
\end{tabular}

$a$ : see Lorenzo Figueiras et al. (1994).
The faeces of T. guasayana evoked a stronger response than those collected from $T$. sordida and $T$. infestans (Fig.). The interaction species-faeces was not significant $(\mathrm{F}=1.224 ; \mathrm{df}=4,60 ; \mathrm{P}=0.31)$.

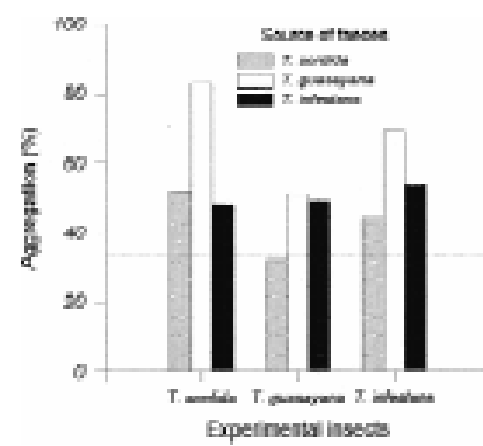

The aggregation response of triatomine larvae to intra- and inlerspecific larval faeces. The horizo
waited from a random distribution.

DISCUSSION

The results presented here extend our knowledge about the aggregation behaviour of Triatominae bugs. An aggregating substance is present in the dry faeces of $T$. infestans, T. sordida

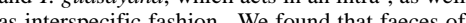
$T$ infestans elicit assem. . n $T$ guasayana. In a similar way, the excrement of the last two named species induces agregation in larvae of $T$ infestans. On the other hand, the faces of $T$ guasayana elicit assembling behaviour in larvae of $T$ sordida, but the inverse is not tour in $T$ sordida do not promote the aggegation of T. guasayana larvae.

Cruz-López et al. (1993) obtained comparable results in their analysis of the aggregation of $T$ mazzottii, T. longipennis, T. pallidipennis, $T$. barberi and $R$. prolixus. The named authors postulated the existence of an "interspecific aggregation pheromone" that would be present in the faeces of larvae and adults of these species. They found that $T$. longipennis larvae showed a stronger response than the other triatomine larvae tested. However, there were no significant differences in faecal attractiveness to larvae.

The biological action of the assembling signal of triatomines deserves to be discussed in the frame of the present classification of chemosignals. Compounds eliciting inter- or intraspecific responses re known as semiochemicals. The term pheromone refers to substances that are secreted by an organism to the outside and cause specific reactions in receptor organisms of the same species. On the other hand, allelochemicals are substances produced, acquired, or released as the result of the activities of an organism, which are capable of evoking a behavioural reaction in a receptor of a different species (Dicke \& Sabelis 1988). Considering that excrement act as a chemical mark for guiding triatomines towards protected sites (Lorenzo \& Lazzari 1996), this landmark (and the refuges) could be exploited for other species, that would benefit from the interaction. Among allelochemicals, such substances that evoke an adaptive response in receptor of other species, have been named kairomones (Dicke \& Sabelis 1988). Our results show that assembling factors in the aeces of Triatominae act as a pheromone for the same species but would also act as a kairomone for individuals of other species. The same kind of interaction has been described between different species of the Order Dermaptera (Sauphanor \& Sureau 1993), where the cohabitation of sheltertraps by species belonging to the genus Forficula has been observed in the field. Other examples are known for such a functional duality of aggregation substances in cockroaches (Appel 1994) and Deetles (Vité \& Renwick 1971).

$T$. infestans is the most widespread and best adapted domestic species of triatomine bugs. $T$. sordida and $T$. guasayana are frequently infected by asease, because they also colonise his or habita-

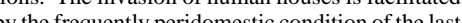
two species (Lent \& Wygodzin 1979). In cent where other species had been eradicated by successful control campaigns has been reported in Brazil (Schofield 1994). In this context, the chemical signal acting in an interspecific fashion relevant, because the bugs of any of the three species could find and exploit the refuges used by conspecifics, as well as by members of the other conspecifics, as well as by members of the other
species. In addition, $T$. sordida and T. infestans hecies. In addition, $T$. sordida and T. infestans localities in Bolivia (Noireau et al. 1995)

The interspecific attractiveness of the faeces of the three species studied here leaves open the question on the origin of the substances involved. The fact that the aggregation "pheromone" acts also interspecifically (i.e., as a kairomone) suggests us that the same, or very similar chemicals, are present in the faeces of the species studied here. It could also indicate that these compounds have a common ancestor. The insects would identify a com- 
mon compound of the signal as specialists, or could have a generalised response to a family of compounds. For example, the interspecific aggregis not strictly a response to a pheromone, since could be due to the attraction of cockroaches to fatty acids (Ishii 1970)

Regarding the chemical nature of the aggregation substance, although Cruz-López and Morgan (1995) did not succeed in obtaining the active fraction by chromatographic fractionating, they showe that the active compounds could be extracted with polar solvents. This result agrees with data obtained in our laboratory (Lorenzo Figueiras, unpublished observations). Recently, Taneja (1996) found that triatomine faeces release ammonia, an that this compound activates specific sensory receptors in the antennae and evokes a positive anemotactic response in both, $R$. prolixus and $T$. infestans. These results point out future research directions to the characterisation of an interspecific aggregation factor, which becomes of fundmental value for controlling and monitoring bu populations in the field.

In the precedent paragraphs, we referred to the proximate causes of this behaviour in triatomine (e.g., sharing of the same or similar assembling signals by different species, exploitation of a widespread metabolic by-product, etc.). Finally, we can speculate on the ultimate evolutionary causes of intraspecific responses, since this aspect opens several relevant questions. One can ask, for example,

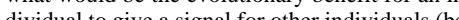
dividual to give a signal for other indiviluals (belonging or hot to the same species) hat might repTriatomine bugs spend light day hous hiden in shelters, where they assemble. As murs hidden in crement functions as a chemical landmat, serves to find the accesses of refuges under ase (Lorenzo \& Lazzari 1996). So, in the case of individuals of the same species, the question could be reformulated as what would be the evolutionary benefit of living in close aggregation. An obvios benefit is easy finding of symbionts, which a essential normal devel $\&$ Friend 1968, Eichler et al. 1996), and, in the case of adults, of sexual mates.

The benefit of the interspecific response appears as not so obvious. Again, the advantage for the receiver could be related to the exploitation of protected places, that are in addition contaminate with the necessary symbionts. The need of symbionts could also be argued as a benefit for the emitter. But, in this case, it should be also take into account that evolutionary constrains (e.g., the lack of certain metabolic pathways) or the balance between costs and benefits of producing a more discrete specific chemi use of a natural metabolic by-product (i.e., ammonia), that is shared by different species.

\section{ACKNOWLEDGEMENTS}

To the staff members of the Laboratory of Insec Physiology for many fruitful discussions and for correcting the manuscript.

\section{REFERENCES}

Appel AG 1994. Intra- and interspecific trappings of two sympatric peridomestic cockroaches (Dic1032

Baldwin WF, Knight AG, Lynn KR 1971. A sex pheromone in the insect Rhodnius prolixus (Hemiptera Reduviidae). Can Entomol 103: 19-22.

Cruz-López L, Morgan D 1995. Chemical investiga(Triatoma bug 2078.

Cruz-López L, Malo EA, Rojas JC 1993. Aggregatio pheromone in five species of Triatominae (Hemiptera: Reduviidae). Mem Inst Oswaldo Cruz 88: 535-

539.
Dicke M, Sabelis M 1988. Infochemical terminology: based on cost-benefit analysis rather than the origi

in S, Reinties N, Jung M, Yasin AF, Sch 1 KP, Junqueira A, Coura JR, Schaub GA 1996. Identifi-
J cation of bacterial isolates and symbionts from wild populations of Triatoma infestans and T. sordida. Mem Inst Oswaldo Cruz 91 (Suppl.): 125.

Gorla DE, Jurberg J, Catalá S, Schofield CJ 1993. Systematics of Triatoma sordida, T. guasayana and $T$ patagonica (Hemiptera: Reduviidae). Mem Ins

hii S 1970. An aggregation pheromone of the German ficity of the pheromone. Appl Entomol Zool 5:33-41

Lake P, Friend WG 1968. The use of artificial diets to determine some of the effects of Nocardia rhodni on the development of Rhodnius prolixus. J Insed Physiol 14: 543-562.

(He Wygodzinsky P 1979. Revision of Triatominae (Hemiptera, Reduviidae), and their significance as 163: $125-520$.

Lorenzo MG, Lazzari CR 1996. The spatial pattern of defecation in Triatoma infestans and the role of faeces as a chemical mark of the refuge. $J$ Insect

Physiol 42: 903-907.
Lorenzo Figueiras AN, Lazzari C 1996. Un factor novedoso de agregación en Triatoma infestan. americano Congreso de Ento-47. VI LatinoNacional, Mérida, México.

Lorenzo Figueiras AN, Kenigsten A, Lazzari CR 1994. Aggregation in haematophagous bug Triatoma infestans: Chemical signals and temporal pattern. $J$
Manrique G, Lazzari CR 1995. Existence of a sex pheromone in Triatoma infestans (Hemiptera: Reduviidae): Behavioural evidence, Mem Inst Oswaldo Cruz 90: 645-648.

Noireau F, Peredo C, Vargas F, Ordoñez J, García S, Bosseno MF, Brenière F, Medinacelli M 1995. Original domiciliation of Triatoma sordida Stal in the department of Santa

Núñez JA, Lazzari CR 1990. Rearing of Triatoma infestans Klug (Heteroptera: Reduviidae) in the ab-
sence of a live host. I. Some factors affecting the artificial feeder. J Appl Entomol 109: 87-92.

Ondarza RN, Gutiérrez-Martínez A, Malo EA 1986. Evidence for the presence of sex and aggregation pheromones from Triatoma mazzottii (Hemipter Reduritac). JEcon Entom $179.688-692$.

and interspecific relationships in Deraviour Oecologia 96: 360-364.
Schofield CJ 1994. Triatominae. Biología y Control, munica Publications, UK, 76 pp.

chofield CJ, Moreman K 1976. Apparent absence of sex attractant in adult Triatoma infestans (Klug), Hyg 70: 165-166.

chofield CJ, Patterson JW 1977. Assembly pheromone of Triatoma infestans and Rhodnius prolixus nymph 734.

Teja J 1996. Sensory and Behavioural Responses of Rhodnius prolixus and Triatoma infestans to Vertebrate Odours and to Volatiles from Triatomine Faeces, PhD Thesis, Université de Neuchâtel, 91 pp. elázquez Antich A 1968. Atracción por olor en ninfas y adultos de Rhodnius prolixus. Rev Inst Med Tro Vité JP, Renwick AA 1971 .

pherom in sect Physiol 17: 1699-1704. 
138 Aggregation Signals in Triatoma • AN Lorenzo Figueiras, CR Lazzari 